\title{
(2) OPEN ACCESS \\ School academic performance of children hospitalised with a chronic condition
}

\author{
Nan Hu (1) ,' Joanna Fardell, ${ }^{2,3}$ Claire E Wakefield, ${ }^{2,3}$ Glenn M Marshall, ${ }^{3}$ \\ Jane C Bell (D) , ${ }^{4}$ Natasha Nassar, ${ }^{4}$ Raghu Lingam ${ }^{1}$
}

\begin{abstract}
- Additional supplemental material is published online only. To view, please visit the journal online (http://dx.doi. org/10.1136/archdischild2020-321285)
\end{abstract}

${ }^{1}$ Population Child Health Research Team, School of Women's and Children's Health, University of New South Wales, Randwick, New South Wales, Australia

${ }^{2}$ Behavioural Sciences Unit, School of Women's and

Children's Health University of New South Wales, Randwick,

New South Wales, Australia

${ }^{3}$ Kids Cancer Centre, Sydney

Children's Hospital Randwick,

Randwick, New South Wales, Australia

${ }^{4}$ Child Population and Translational Health Research, Children's Hospital at Westmead, The University of Sydney, Westmead, New South Wales, Australia

\section{Correspondence to}

Dr Nan Hu, Population Child Health Research Team, School of Women's and Children's Health, University of New South Wales, Randwick, NSW 2031, Australia; nan.hu@unsw.edu.au

$\mathrm{NH}$ and JF are joint first authors.

$\mathrm{NN}$ and RL are joint senior authors.

Received 10 February 2021 Accepted 5 August 2021 Published Online First 2 September 2021

\author{
ABSTRACT \\ Objective To examine academic outcomes among \\ children hospitalised with a chronic health condition. \\ Design Population-level birth cohort. \\ Setting New South Wales, Australia. \\ Participants 397169 children born 2000-2006 \\ followed up to 2014
}

Intervention/exposure Hospitalisations with a chronic condition.

Main outcome measures Academic

underperformance was identified as 'below the national minimum standard' (BNMS) in five literacy/numeracy domains using the national assessment (National Assessment Program-Literacy and Numeracy) data. Multivariable logistic regression assessed the adjusted ORs (aORs) of children performing BNMS in each domain at each grade (grades 3, 5 and 7, respectively).

Results Of children hospitalised with a chronic condition prior to National Assessment Program-Literacy and Numeracy (NAPLAN) (16\%-18\%), 9\%-12\% missed $\geq 1$ test, with a maximum of $37 \%$ of those hospitalised $\geq 7$ times, compared with $4 \%-5 \%$ of children not hospitalised. Excluding children who missed a NAPLAN test, more children hospitalised with a chronic condition performed BNMS across all domains and grades, compared with children not hospitalised (eg, for BNMS in reading at grade 3: $n=2588$, aOR $1.35(95 \%$ Cl 1.28 to 1.42); for BNMS in numeracy at grade 3: $\mathrm{n}=2619$, aOR $1.51(95 \% \mathrm{Cl} 1.43$ to 1.59)). Increasing frequency and bed-days of hospitalisation were associated with 2-3 fold increased odds of performing BNMS across all domains and grades. Children hospitalised with mental health/behavioural conditions had the highest odds of performing BNMS across all domains at each grade.

Conclusions Children hospitalised with a chronic condition underperform academically across literacy/ numeracy domains at each school grade. Health and educational supports are needed to improve these children's academic outcomes.

\section{INTRODUCTION}

At least $10 \%$ of children aged less than 14 years live with one or more chronic health conditions. ${ }^{1}$ These conditions limit independent living and social interactions, often requiring ongoing medical interventions including hospitalisation. ${ }^{2}$ Over the last two decades, the number of children living with chronic conditions has increased two-fold, mostly due to improved treatments enabling severely ill children to live longer. ${ }^{3}$ Chronic conditions account for $62 \%$ of all disability adjusted life years lost and 70\% of

\section{WHAT IS ALREADY KNOWN ON THIS TOPIC?}

$\Rightarrow$ Children with a chronic condition have $30 \%-$ $40 \%$ increased risk of performing below the basic academic requirements compared with children without chronic conditions.

$\Rightarrow$ Children with a chronic condition, particularly those with severe symptoms, are more likely to be hospitalised frequently or longer, which can interrupt their school attendance and engagement in learning and social interactions that are vital for academic performance.

\section{WHAT THIS STUDY ADDS?}

$\Rightarrow$ Children hospitalised with a chronic condition were more likely to miss testing and, if they complete testing, underperform in various literacy/numeracy domains at primary and secondary grades. Additionally, the more hospital admissions or bed-days, the poorer the academic performance.

$\Rightarrow$ Children hospitalised with mental health/ behavioural conditions had a higher risk of poor academic performance compared with those hospitalised with other chronic conditions.

$\Rightarrow$ Children with chronic conditions need integrated health and educational interventions to improve their academic outcomes.

deaths for children under 15 years in high-income countries. ${ }^{45}$

Educational attainment in literacy and numeracy is a crucial component of human capital, with profound implications for society's economic productivity. ${ }^{6}$ For example, each $1 \%$ increase in school students' academic outcomes across the Organisation for Economic Co-operation and Development (OECD) countries brings about an average of $0.3 \%$ increase in the gross domestic product (GDP) growth (equivalent to US\$3 billion$).^{7}$

Despite the importance of academic outcomes and the increasing prevalence of childhood chronic conditions, few studies have systematically quantified the impact of chronic conditions on academic outcomes. Previous work has demonstrated that preschool-aged children hospitalised for a chronic condition have increased developmental vulnerability that impact their readiness to start school. ${ }^{89}$ These difficulties appear to affect a child's academic outcomes as they progress through school, with a 
$30 \%-40 \%$ increased risk of academic underperformance for children with a chronic condition. ${ }^{10} 11$

However, previous research has been limited by focusing on one or two specific chronic conditions, ${ }^{12}{ }^{13}$ using parentreported chronic conditions that may be clinically unverified and subject to recall bias, especially for detailed information such as frequency and duration of healthcare utilisation, ${ }^{10} 11$ and often failed to consider academic outcomes at different grades. ${ }^{10} 1114$ More importantly, no studies have examined academic outcomes of children hospitalised with a chronic condition. This vulnerable group tends to have severe or inadequately controlled symptoms that require ongoing hospital treatment, ${ }^{15}$ potentially leading to high levels of school absenteeism, low levels of school engagement ${ }^{1116}$ and ultimately to poor academic outcomes at school.

Therefore, we aimed to examine the academic outcomes of children hospitalised with a chronic condition. We examined how frequency and duration of hospitalisations-proxy markers for condition severity-were associated with children's literacy and numeracy outcomes at three school grades, compared with children who were not hospitalised. We also compared children hospitalised with a chronic condition to those hospitalised without any chronic conditions to explore whether educational outcomes are associated with chronic conditions among children who have ever been hospitalised. This study is part of the Kids to Adults Chronic Illness Alliance research programme, which aims to promote academic performance for children hospitalised with a chronic condition. ${ }^{17}$

\section{METHODS}

\section{Study design}

We analysed data from a population-based cohort including all children born between 2000 and 2006 in New South Wales (NSW), Australia, using records routinely collected at birth, hospital inpatient admissions and school assessment (the National Assessment Program-Literacy and Numeracy or NAPLAN) in NSW.

As this study aimed to understand educational outcomes at each grade, we created three grade cohorts: grade 3 cohort including children with a NAPLAN record at grade 3 , grade 5 cohort including those with a NAPLAN record at grade 5 and grade 7 cohort including those with a NAPLAN record at grade 7 (online supplemental figure 1). Children were included in more than one cohort if they had NAPLAN outcomes at different grades. However, we conducted the analysis for each grade separately; thus, each child only appeared once in each respective analysis.

\section{Outcomes}

NAPLAN is Australia's standardised school assessment administered nationwide to evaluate students' academic skills in five domains: reading, writing, spelling, grammar and punctuation, and numeracy. NAPLAN scores have been shown to predict subsequent access to tertiary education. ${ }^{18}$ Since 2008 , all children in grades 3 (age 7-9 years), 5 (9-11 years), 7 (11-13 years) and 9 (unavailable for this study) sit NAPLAN tests annually, and the results are comparable across testing years. We identified school academic outcomes using NAPLAN data collected between 2009 and 2014. Data were only available for children attending government schools, consisting of two thirds of all NSW school students.

For each grade, performing below the national minimum standard (BNMS) was analysed as the primary outcome. Children who performed BNMS are considered to lack the basic skills expected to successfully progress through schooling without additional support. ${ }^{19}$ As NAPLAN data were unavailable for children who did not sit a test, these children were assessed separately.

\section{Exposures}

We analysed hospital admission records from all NSW public and private hospitals since 2001. Each record contains up to 50 diagnostic fields, coded using the International Statistical Classification of Diseases and Related Health Problems, 10th Revision, Australian Modification system (ICD-10-AM). ICD codes were used to identify eight categories of paediatric chronic conditions, including cancer, respiratory, neurological, metabolic and mental health conditions (online supplemental table 1 ) ${ }^{20}$ For each grade cohort, we categorised children into three exclusive groups: children hospitalised with a chronic condition, children hospitalised without any chronic conditions and children without any recorded hospitalisations (comparison group).

To ensure temporal sequence, we only identified hospitalisations that occurred before the NAPLAN test for each grade cohort (ie, prior to grade 3 test for grade 3 cohort, prior to grades 5 and 7 test for grades 5 and 7 cohort, respectively). Children hospitalised with a chronic condition were categorised by their total frequency (1, 2-3, 4-6 and $\geq 7$ admissions) and bed-days (1-2, 3-4, 5-7, 8-14 and $\geq 15$ days) of hospitalisations with a chronic condition. Hospitalisations that occurred within 29 days of birth are predominantly birth related and hence were removed.

\section{Covariates}

We included as covariates child's sex and age at the test, perinatal factors such as birth weight and gestation, familial socioeconomic factors and child's birth year controlled for potential cohort effects (table 1). Residence socioeconomic status and remoteness were determined using the national index for socioeconomic disadvantage ${ }^{21}$ and geographic location, ${ }^{22}$ respectively.

\section{Data analysis}

We conducted three separate analyses using each grade cohort, where grade 3 cohort was used only to examine children's educational outcomes at grade 3, and grade 5 and grade 7 cohorts were used only to examine children's educational outcomes at grades 5 and 7, respectively (online supplemental figure 1). We first compared the characteristics of children hospitalised with and without a chronic condition and children without any hospitalisations. We then examined the proportion of children who missed a NAPLAN test and the proportion of children who sat the test but performed BNMS. We conducted logistic regression analysis to examine the ORs of performing BNMS in each NAPLAN domain at grades 3, 5 and 7, respectively, for children hospitalised with and without a chronic condition, compared with those without any hospitalisations, controlling for all covariates. Furthermore, we examined the ORs of performing BNMS associated with the frequency, duration and diagnosis of hospitalisations for children hospitalised with a chronic condition, compared with those without any hospitalisations. We also examined the ORs of performing BNMS for children hospitalised with a chronic condition compared with those hospitalised without any chronic conditions by further controlling for the total length of hospitalisations for any health conditions. ${ }^{23}$ Missing data were minimal for all confounders $(\leq 0.8 \%)$ except for parents' educational attainment (multiple imputation for $7 \%$ missing values resulted in consistent outcomes). We controlled 
Table 1 Characteristics of children with a NAPLAN record at grade 3

\begin{tabular}{|c|c|c|c|}
\hline & $\begin{array}{l}\text { Children without recorded } \\
\text { hospitalisations prior to NAPLAN } \\
\text { assessment at grade } 3\end{array}$ & $\begin{array}{l}\text { Children hospitalised without any } \\
\text { chronic conditions prior to NAPLAN } \\
\text { assessment at grade } 3\end{array}$ & $\begin{array}{l}\text { Children hospitalised with a } \\
\text { chronic condition prior to NAPLAN } \\
\text { assessment at grade } 3\end{array}$ \\
\hline Factors & n (column \%) & n (column \%) & n (column \%) \\
\hline All & $147456(100)$ & $105033(100)$ & $50091(100)$ \\
\hline \multicolumn{4}{|l|}{ Child's sex } \\
\hline Male & $68324(46.3)$ & $58242(55.5)$ & $29931(59.8)$ \\
\hline Female & $79060(53.6)$ & $46748(44.5)$ & $20125(40.2)$ \\
\hline Unknown & $72(0.1)$ & $43(0.0)$ & $35(0.1)$ \\
\hline \multicolumn{4}{|l|}{ Child perinatal factors } \\
\hline \multicolumn{4}{|l|}{ Gestational age (weeks) } \\
\hline Preterm birth (gestational age $\leq 36$ ) & $7716(5.2)$ & $7754(7.4)$ & $4919(9.8)$ \\
\hline Term birth (gestational age: $37-41$ ) & $135894(92.2)$ & $94965(90.4)$ & $44093(88.0)$ \\
\hline Post-term birth (gestational age $\geq 42$ ) & $3833(2.6)$ & $2297(2.2)$ & $1074(2.1)$ \\
\hline Missing & $13(0.0)$ & $17(0.0)$ & $\therefore(--)$ \\
\hline \multicolumn{4}{|l|}{ Birth weight by gestation } \\
\hline Small for gestation $(<10 \%)$ & $15593(10.6)$ & $12073(11.5)$ & $6116(12.2)$ \\
\hline Birth weight by gestation: $10 \%-90 \%$ & $117038(79.4)$ & $82522(78.6)$ & $38766(77.4)$ \\
\hline Large for gestation ( $\geq 90 \%$ ) & $14606(9.9)$ & $10229(9.7)$ & $5084(10.2)$ \\
\hline Missing & $219(0.2)$ & $209(0.2)$ & $125(0.3)$ \\
\hline \multicolumn{4}{|l|}{ Plurality } \\
\hline Singleton & $143534(97.3)$ & $101532(96.7)$ & $48275(96.4)$ \\
\hline Twins or others & $3922(2.7)$ & $3501(3.3)$ & $1816(3.6)$ \\
\hline \multicolumn{4}{|l|}{ Apgar score (5 min) } \\
\hline $5 \min$ Apgar: $<7$ & $1542(1.1)$ & $1368(1.3)$ & $975(2.0)$ \\
\hline 5 min Apgar: 7-10 & $145571(98.7)$ & $103446(98.5)$ & $48997(97.8)$ \\
\hline Missing & $343(0.2)$ & $219(0.2)$ & $119(0.2)$ \\
\hline \multicolumn{4}{|c|}{ Maternal and familial socioeconomic factors } \\
\hline \multicolumn{4}{|l|}{ Maternal parity } \\
\hline First-born child & $58863(39.9)$ & $43772(41.7)$ & $21476(42.9)$ \\
\hline Second-born child & $50928(34.5)$ & $34569(32.9)$ & $16487(32.9)$ \\
\hline Third-born child or younger & $37575(25.5)$ & $26620(25.3)$ & $12112(24.2)$ \\
\hline Missing & $90(0.1)$ & $72(0.1)$ & $16(0.0)$ \\
\hline \multicolumn{4}{|l|}{ Gestational weeks at first antenatal visit } \\
\hline Antenatal care $<20$ weeks & $127510(86.5)$ & $91013(86.7)$ & $43444(86.7)$ \\
\hline Antenatal care $\geq 20$ weeks & $19000(12.9)$ & $13159(12.5)$ & $6190(12.4)$ \\
\hline Missing & $946(0.6)$ & $861(0.8)$ & $457(0.9)$ \\
\hline \multicolumn{4}{|l|}{ Maternal smoking during pregnancy } \\
\hline Yes & $24919(16.9)$ & $21833(20.8)$ & $10140(20.2)$ \\
\hline No & $122302(82.9)$ & $83075(79.1)$ & $39880(79.6)$ \\
\hline Unknown & $235(0.2)$ & $125(0.1)$ & $71(0.1)$ \\
\hline \multicolumn{4}{|l|}{ Maternal age at child's birth (years) } \\
\hline$<20$ & $6338(4.3)$ & $6235(5.9)$ & $2664(5.3)$ \\
\hline $20-24$ & $21939(14.9)$ & $18576(17.7)$ & $8558(17.1)$ \\
\hline $25-34$ & $89576(60.8)$ & $62037(59.1)$ & $29810(59.5)$ \\
\hline $35-39$ & $24395(16.5)$ & $15025(14.3)$ & $7436(14.8)$ \\
\hline$\geq 40$ & $5161(3.5)$ & $3125(3.0)$ & $1608(3.2)$ \\
\hline Missing & $47(0.0)$ & $35(0.0)$ & $15(0.0)$ \\
\hline \multicolumn{4}{|c|}{ Maternal postcode-level residential socioeconomic disadvantage (IRSD)* } \\
\hline$\leq 25 \%$ (most disadvantaged) & $30774(20.9)$ & $23658(22.5)$ & $10505(21.0)$ \\
\hline$>25 \%$ and $<=50 \%$ & $36451(24.7)$ & $27597(26.3)$ & $12199(24.4)$ \\
\hline$>50 \%$ and $<=75 \%$ & $39703(26.9)$ & $26930(25.6)$ & $12974(25.9)$ \\
\hline$>75 \%$ (least disadvantaged) & $40433(27.4)$ & $26791(25.5)$ & $14388(28.7)$ \\
\hline Missing & $95(0.1)$ & $57(0.1)$ & $25(0.1)$ \\
\hline \multicolumn{4}{|c|}{ Maternal postcode-level residential remoteness (ARIA) $\dagger$} \\
\hline Major cities of Australia & $114835(77.9)$ & $77687(74)$ & $38674(77.2)$ \\
\hline Inner regional Australia & $24525(16.6)$ & $19739(18.8)$ & $8379(16.7)$ \\
\hline Outer regional Australia & $7355(5.0)$ & $6703(6.4)$ & $2638(5.3)$ \\
\hline
\end{tabular}


Table 1 Continued

\begin{tabular}{|c|c|c|c|}
\hline \multirow[b]{2}{*}{ Factors } & \multirow{2}{*}{$\begin{array}{l}\text { Children without recorded } \\
\text { hospitalisations prior to NAPLAN } \\
\text { assessment at grade } 3 \\
\mathrm{n} \text { (column \%) }\end{array}$} & \multirow{2}{*}{$\begin{array}{l}\text { Children hospitalised without any } \\
\text { chronic conditions prior to NAPLAN } \\
\text { assessment at grade } 3 \\
\text { n (column \%) }\end{array}$} & \multirow{2}{*}{$\begin{array}{l}\text { Children hospitalised with a } \\
\text { chronic condition prior to NAPLAN } \\
\text { assessment at grade } 3 \\
\mathrm{n} \text { (column \%) }\end{array}$} \\
\hline & & & \\
\hline Remote and very remote Australia & $683(0.5)$ & $868(0.8)$ & $387(0.8)$ \\
\hline Unknown & $58(0.0)$ & $36(0.0)$ & $13(0.0)$ \\
\hline \multicolumn{4}{|l|}{ Maternal country of birth } \\
\hline Australia born & $105142(71.3)$ & $80657(76.8)$ & $38619(77.1)$ \\
\hline Non-Australia born & $42314(28.7)$ & $24376(23.2)$ & $11472(22.9)$ \\
\hline \multicolumn{4}{|c|}{ Parental highest educational attainment $\neq$} \\
\hline Year 12 or equivalent or below & $31790(21.6)$ & $25522(24.3)$ & $11415(22.8)$ \\
\hline Certificate or diploma & $61036(41.4)$ & $44674(42.5)$ & $21091(42.1)$ \\
\hline Bachelor's degree or above & $44109(29.9)$ & $26582(25.3)$ & $13629(27.2)$ \\
\hline Missing & $10521(7.1)$ & $8255(7.9)$ & $3956(7.9)$ \\
\hline \multicolumn{4}{|l|}{ Child's age at NAPLAN grade 3 test } \\
\hline 7 years & $9375(6.4)$ & $5796(5.5)$ & $2341(4.7)$ \\
\hline 8 years & $121755(82.6)$ & $85437(81.3)$ & $39870(79.6)$ \\
\hline 9 years & $16266(11.0)$ & $13763(13.1)$ & 7835 (15.6) \\
\hline Other & $60(0.0)$ & $37(0.0)$ & $45(0.1)$ \\
\hline \multicolumn{4}{|l|}{ Child's year of birth } \\
\hline 2000 & $16186(11.0)$ & $12647(12.0)$ & $5918(11.8)$ \\
\hline 2001 & $23403(15.9)$ & $17946(17.1)$ & $8313(16.6)$ \\
\hline 2002 & $23854(16.2)$ & $17577(16.7)$ & $8439(16.9)$ \\
\hline 2003 & $24396(16.5)$ & $17343(16.5)$ & 8315 (16.6) \\
\hline 2004 & $24373(16.5)$ & 16888 (16.1) & 8308 (16.6) \\
\hline 2005 & 26630 (18.1) & 17417 (16.6) & 8375 (16.7) \\
\hline 2006 & $8614(5.8)$ & $5215(5.0)$ & $2423(4.8)$ \\
\hline
\end{tabular}

*Maternal postcode-level residential socioeconomic disadvantage was measured using the Index of Relative Socioeconomic Disadvantage (IRSD) score.

† Maternal postcode-level residential remoteness was determined using the Accessibility/Remoteness Index of Australia (ARIA) classification.

¥Parental highest educational attainment was measured at the time of the child's NAPLAN grade 3 test.

$\S$ Numbers from 1 to 5 are suppressed from presentation to protect individual confidentiality.

NAPLAN, National Assessment Program-Literacy and Numeracy.

for school-level clustering in the NAPLAN outcomes of children from the same school using generalised estimating equations. The SEs of the regression coefficients and the $95 \%$ CIs were estimated using the empirical estimation method. All analyses were conducted using SAS (Enterprise Guide) statistical software V.7.1 (SAS Institute).

\section{RESULTS}

Of children born 2000-2006, 302580 had a NAPLAN record at grade 3, 201995 at grade 5 and 85307 at grade 7 before 2014 (online supplemental table 2). The proportion of children hospitalised with a chronic condition prior to the test was $16.6 \%(\mathrm{n}=50091)$ for grade $3,17.5 \%(\mathrm{n}=35419)$ for grade 5 and $18.2 \%(\mathrm{n}=15555)$ for grade 7 . Compared with children without hospitalisations, more children hospitalised with and without a chronic condition were boys $(59.8 \%$ vs $46.3 \%)$ and experienced perinatal and socioeconomic difficulties (table 1, online supplemental tables 3 and 4). Among children hospitalised with a chronic condition, the most common diagnoses were asthma (33\%), chronic ear conditions (20\%) and other respiratory conditions such as sleep disorders (20\%). Common diagnoses for children hospitalised without chronic conditions are shown in online supplemental table 5.

Around $10 \%$ of children hospitalised with a chronic condition prior to testing missed the test across grades, compared with 5\%-7\% of children hospitalised without any chronic conditions and $3 \%-5 \%$ of children without hospitalisations.
The proportion of children missing a test increased with higher frequency or duration of hospitalisations, irrespective of grade (figure 1, online supplemental table 6).

Among children who sat the test, those hospitalised with a chronic condition had increased odds of performing BNMS in all NAPLAN domains at each grade, compared with those without recorded hospitalisations. Generally, the aORs were lower for reading (aOR ranging from 1.35 at grades 3 to 1.49 at grade 7) and slightly higher for numeracy (aOR ranging from 1.51 at grade 3 to 1.58 at grade 7). Children hospitalised without any chronic conditions had significantly higher odds of performing BNMS than those without any hospitalisations but lower than those hospitalised with a chronic condition across NAPLAN domains and school grades (aORs ranging from 1.13 to 1.25 ) (online supplemental tables 7 and 8).

Figure 2 (derived from online supplemental tables 9-13) demonstrates that increasing frequency of hospitalisations with a chronic condition was associated with higher odds of performing BNMS across all domains. Results for reading and numeracy are described in more detail as exemplars due to their core academic importance. Children hospitalised with a chronic condition once had 25\% increased odds of performing BNMS in reading at grades 3 and 5, and 37\% increased odds in reading at grade 7 , with $36 \%-42 \%$ increased odds of performing BNMS in numeracy. Children hospitalised $\geq 7$ times had doubled odds of performing BNMS for reading and nearly tripled odds for numeracy across the three grades. 

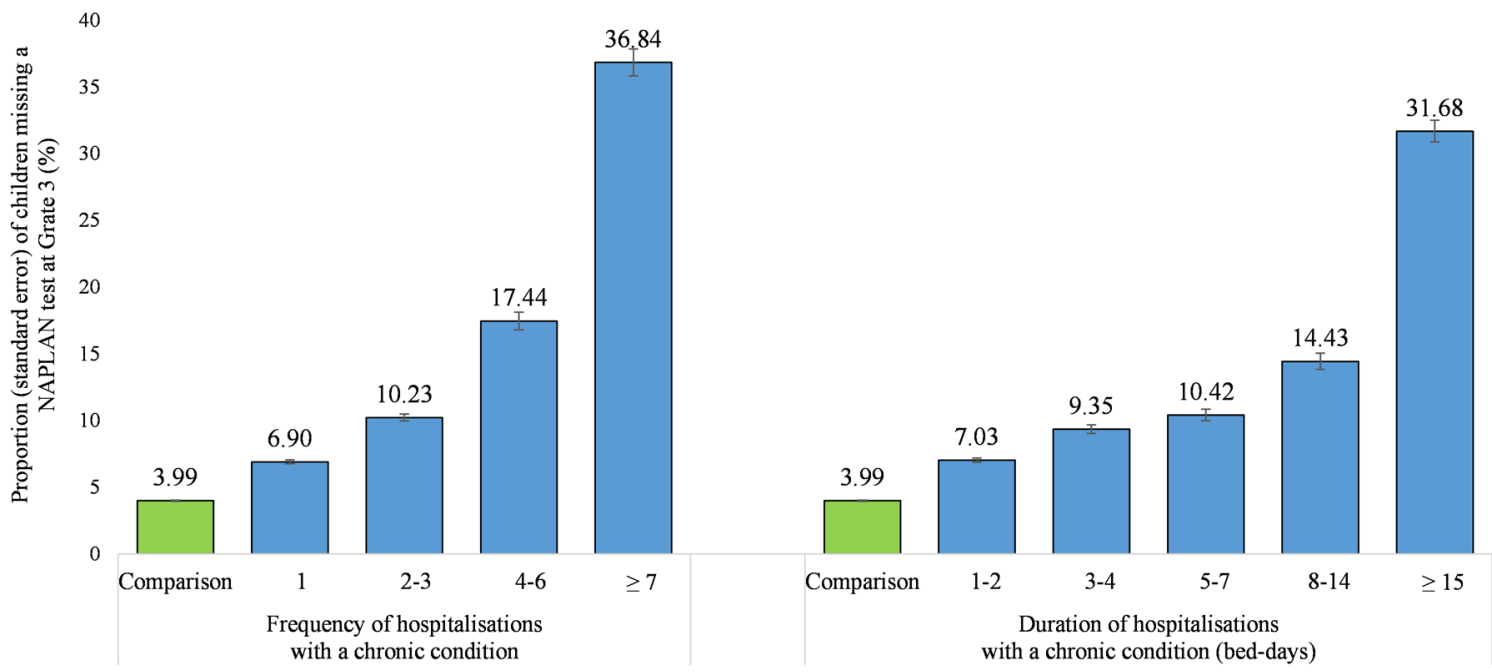

Figure 1 Proportion of children missing a NAPLAN test at grade 3 due to any reason for those hospitalised with a chronic condition and those without any recorded hospitalisation (reference) prior to the test. Comparison group is children without any recorded hospitalisation prior to the test. We confirm that we have permission to reuse the image, because this was created by the first author. NAPLAN, National Assessment Program-Literacy and Numeracy.

Figure 3 (derived from online supplemental tables 9-13) shows a similar pattern with increasing duration of hospitalisations. Children hospitalised with a chronic condition for 1-2 days had 30\%-38\% increased odds of performing BNMS in reading, and $40 \%-47 \%$ increased odds of performing BNMS in numeracy across the three grades. Children hospitalised $\geq 15$ days had doubled odds of performing BNMS for both reading and numeracy at each grade.

Children hospitalised with mental health/behavioural conditions (accounting for 7\%-10\% of all admissions related to chronic conditions) had the highest odds of performing BNMS across all domains at each grade (online supplemental tables 14-18), with around 2.5-fold increased odds for reading and over threefold for numeracy. Children hospitalised with cardiovascular or neurological conditions had the second highest odds of performing BNMS across domains at each grade (aOR ranged from 1.60 to 2.00). Furthermore, children hospitalised with more bed-days had a higher percentage of performing BNMS regardless of diagnosis (online supplemental tables 19-20).

\section{DISCUSSION}

To our knowledge, this is the first study to examine the full magnitude of academic outcomes of children hospitalised with a chronic condition using a large population-based dataset. Our results show that over $30 \%$ of the most severely affected children (ie, hospitalised $\geq 7$ times or for $\geq 15$ days) missed testing, and those who sat the test had 1.25 to threefold increased risk of falling below basic milestones across academic domains and school grades. Previous research has shown children who miss testing are likely to have the worst academic outcomes. ${ }^{24}$ As such, our results are likely to underestimate the true risk of academic under-performance in children hospitalised with a chronic condition.

Our results are supported by previous findings that may explain the association between chronic conditions and academic outcomes. Children with a chronic condition have a 30\%-80\% increased risk of missing school due to recurrent hospitalisations for treatment of the condition. ${ }^{11}$ This can lead to chronic school absenteeism, which impacts children's engagement in school learning and affects their motivation to succeed academically. ${ }^{25}$ Children with a chronic condition may also experience difficult peer relationships, ${ }^{26}$ interfering with their normal development of socioemotional and cognitive competence that are vital for academic outcomes. ${ }^{27}$

We found that children hospitalised only once or for 1-2 days had a $30 \%-50 \%$ increased risk of academic underperformance. These children were mostly hospitalised for asthma or chronic ear infections. These hospitalisations are a strong marker for inadequate symptom control, which can lead to long-lasting and severe symptoms requiring ongoing hospital treatment. ${ }^{1528}$ Therefore, hospitalisations for these conditions, even briefly, should be taken seriously as they signify the need for critical early interventions. Strong evidence shows appropriate medical action plans can improve the child's quality of life $^{20}$ and potentially minimise the impact of their illness on their academic outcomes.

Children hospitalised with mental health or behavioural conditions were the most vulnerable to poor academic outcomes. Community-based research has shown a lag of 7-11 months in academic outcomes at primary school and 1.3-2.2 years at high school between children with and without mental health/ behavioural problems. ${ }^{29}$ This gap may become even greater for children with more severe mental health conditions that require hospitalisations. Thus, there is urgent need for integrated, potentially hospital-based, psychological and educational interventions for children requiring hospitalisation for mental health conditions. ${ }^{30}$

Our finding that hospitalisation was more strongly associated with declines in numeracy than literacy is supported by previous research showing decreased attendance resulted in greater declines in numeracy than reading scores. ${ }^{31}$ However, there are mixed findings about the impact of chronic conditions on different academic domains. Children with cancer had a progressive deterioration in mathematics, but language and verbal abilities were less affected. ${ }^{32}$ Conversely, mental health problems may have greater impacts on writing/grammar than numeracy. ${ }^{29}$ These findings highlight the importance of 


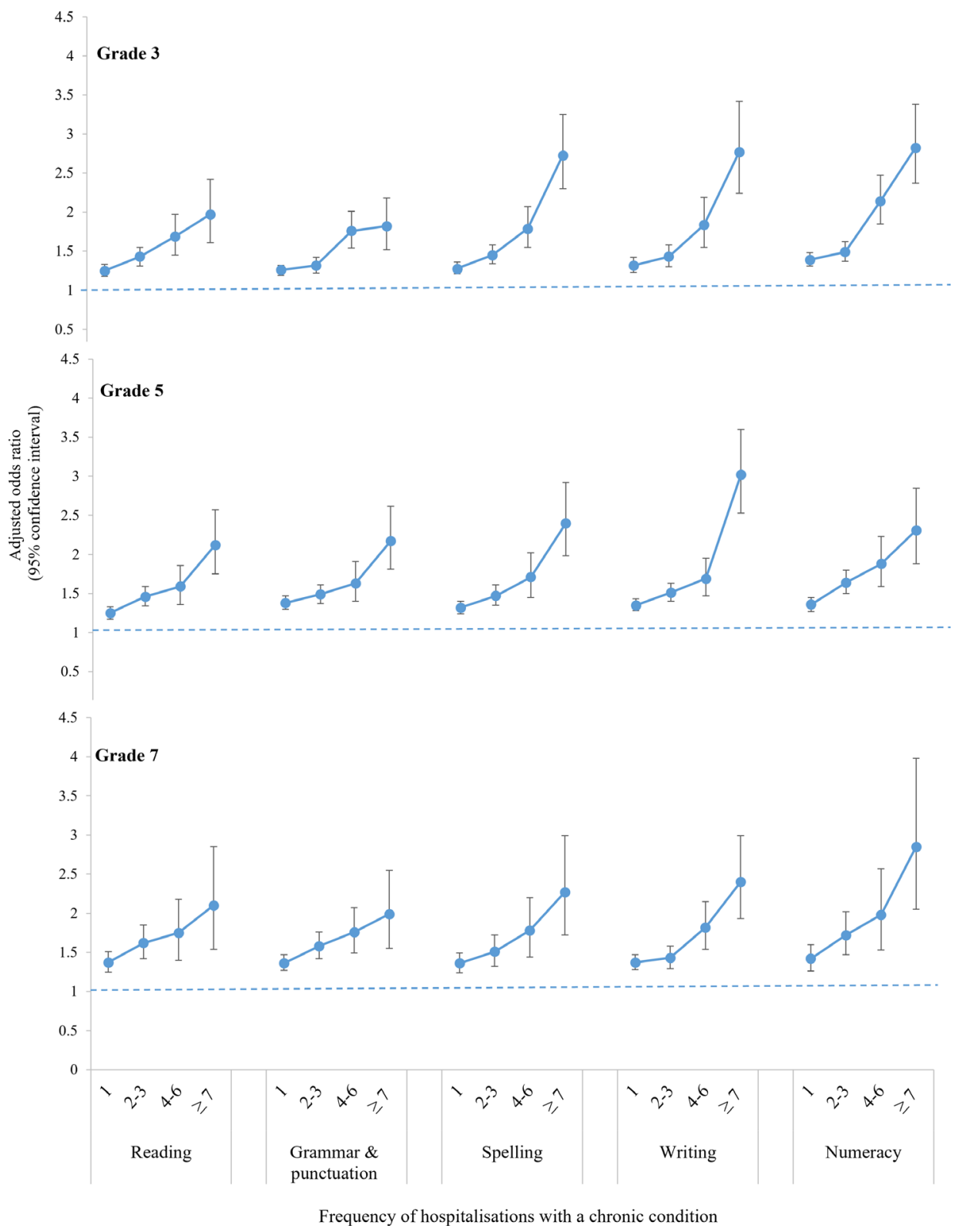

Figure 2 Adjusted ORs (aORs) of children performing BNMS across NAPLAN domains by frequency of hospitalisations with a chronic condition. Comparison group is children without any recorded hospitalisation prior to the test. The aORs were derived from the multivariable logistic regression analyses controlling for school-level clustering effect and all covariates including child's sex, child's perinatal factors (gestational age, birth weight by gestation, plurality and Apgar score), maternal and familial socioeconomic factors (maternal parity, gestation of first antenatal care, maternal smoking, maternal age at child's birth, maternal country of birth, Aboriginality, maternal postcode-level residential socioeconomic status and remoteness at child's birth and parental highest educational attainment), child's age at the NAPLAN test and child's year of birth. We confirm that we have permission to reuse the image, because this was created by the first author. BNMS, below the national minimum standard; NAPLAN, National Assessment Program-Literacy and Numeracy.

targeted literacy and numeracy supports for children affected by different chronic conditions.

Our study had several limitations. First, our use of hospital data meant we were unable to capture children who had a chronic condition but were never hospitalised. However, our results show number and length of hospitalisations may impact academic outcomes beyond the presence of chronic conditions per se. Second, data were unavailable for important mediators, such as absenteeism (although we examined beddays as a proxy) and health and educational support received. Data were also unavailable for NAPLAN outcomes of nongovernment school students who may have better health and educational support. Thus, the association between hospitalisations and academic underperformance may be smaller for these children. Furthermore, there were slightly increased odds of academic underperformance at grade 7 than grades 3 and 5, suggesting an increasing academic gap over time. However, with grade 9 data unavailable, we were unable to test if this gap worsens throughout secondary school. Finally, our large sample became small when we looked at the duration of hospitalisations by diagnosis, which needs to be rigorously examined in the future to inform targeted interventions for children with different conditions. 


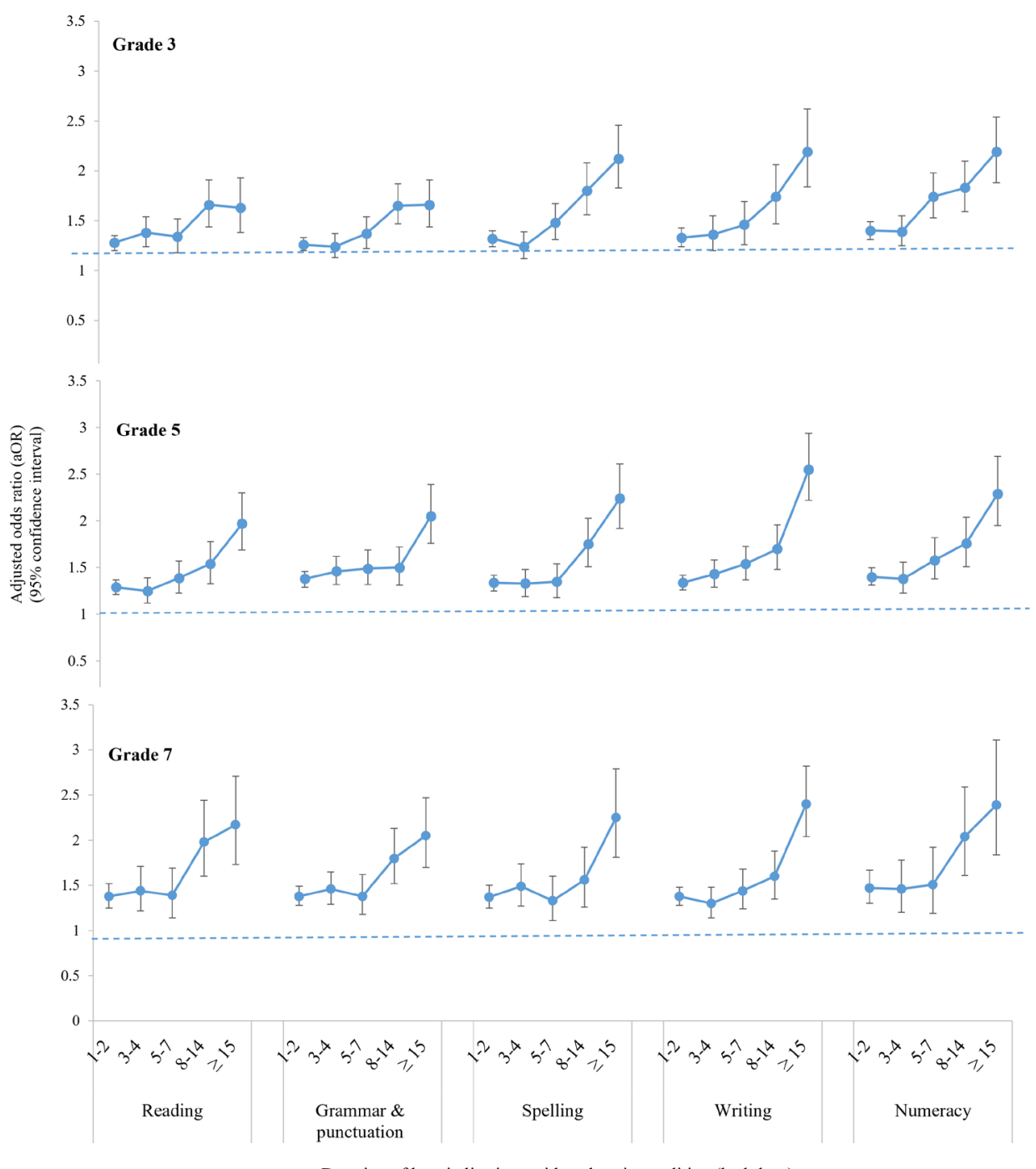

Duration of hospitalisations with a chronic condition (bed-days)

Figure 3 Adjusted ORs (aORs) of children performing BNMS across NAPLAN domains by duration (bed-days) of hospitalisations with a chronic condition. Comparison group is children without any recorded hospitalisation prior to the test. The aORs were derived from the multivariable logistic regression analyses controlling for school-level clustering effect and all covariates including child's sex, child's perinatal factors (gestational age, birth weight by gestation, plurality and Apgar score), maternal and familial socioeconomic factors (maternal parity, gestation of first antenatal care, maternal smoking, maternal age at child's birth, maternal country of birth, Aboriginality, maternal postcode-level residential socioeconomic status and remoteness at child's birth, and parental highest educational attainment), child's age at the NAPLAN test and child's year of birth. We confirm that we have permission to reuse the image, because this was created by the first author. BNMS, below the national minimum standard; NAPLAN, National Assessment Program-Literacy and Numeracy.

\section{CONCLUSION}

In this large, population-based study, we showed children hospitalised with a chronic condition, especially those hospitalised more frequently or for longer, had an increased risk of poor academic performance across literacy and numeracy domains in both primary and secondary grades. These children need to be supported with novel, integrated health and educational interventions.

Acknowledgements The authors would like to acknowledge the support of the Maridulu Budyari Gumal, The Sydney Partnership for Health, Education, Research \& Enterprise (SPHERE) Kids to Adults (K2A) Clinical Academic Group. This research was supported by the use of population data from the Australian Government Department of Education and NSW Ministry of Health. However, the findings and views reported in this article are those of the authors and should not be attributed to these departments. We also acknowledge the New South Wales Centre for Health
Record Linkage for linking the data sets. We would like to thank Nicola Paul for her help in proofreading the manuscript.

Contributors NH conceived this study and established the study protocol, contributed to literature search, analysed the data, prepared the manuscript and critically reviewed the results and manuscripts. RL, NN and JF conceived this study and established the study protocol, contributed to literature search and critically reviewed the results and manuscripts. CW, GMM and JCB contributed to literature search and critically reviewed the results and manuscripts. All authors approved the final manuscript as submitted and agree to be accountable for all aspects of the work.

Funding JF is supported by the Kids Cancer Project. CW is supported by a Career Development Fellowship from the National Health and Medical Research Council of Australia (APP1143767). RL and NN are funded by the Financial Markets Foundation for Children.

Disclaimer The funders of the study had no role in study design, data collection, data analysis, data interpretation or writing of the manuscript. No authors were paid to write this article by a pharmaceutical company or other agency. The first 
and corresponding authors had full access to all the data in the study and had final responsibility for the decision to submit for publication.

Competing interests None declared.

Patient consent for publication Not required.

Ethics approval This study was approved by the NSW Population and Health Services Research Ethics Committee (2012/12/430).

Provenance and peer review Not commissioned; externally peer reviewed.

Data availability statement Data are available on reasonable request. Data may be obtained from a third party and are not publicly available. Individual records for each child were linked across datasets using a probabilistic approach by the NSW Centre for Health Record Linkage. Only de-identified data were provided to the researchers. These data can be requested to the CHeReL (https://www.cherel.org.au/) upon the approval of EOI.

Supplemental material This content has been supplied by the author(s). It has not been vetted by BMJ Publishing Group Limited (BMJ) and may not have been peer-reviewed. Any opinions or recommendations discussed are solely those of the author(s) and are not endorsed by BMJ. BMJ disclaims all liability and responsibility arising from any reliance placed on the content. Where the content includes any translated material, BMJ does not warrant the accuracy and reliability of the translations (including but not limited to local regulations, clinical guidelines, terminology, drug names and drug dosages), and is not responsible for any error and/or omissions arising from translation and adaptation or otherwise.

Open access This is an open access article distributed in accordance with the Creative Commons Attribution Non Commercial (CC BY-NC 4.0) license, which permits others to distribute, remix, adapt, build upon this work non-commercially, and license their derivative works on different terms, provided the original work is properly cited, appropriate credit is given, any changes made indicated, and the use is non-commercial. See: http://creativecommons.org/licenses/by-nc/4.0/.

\section{ORCID iDs}

Nan Hu http://orcid.org/0000-0002-0516-0738

Jane C Bell http://orcid.org/0000-0001-6940-6517

\section{REFERENCES}

1 Agency for Healthcare Research and Quality. Chronic condition indicator (CCI) for ICD-9-CM. Rockville, MD; healthcare cost and utilization project: Rockville, MD; healthcare cost and utilization project, 2011. Available: https://www.hcup-us.ahrq. gov/toolssoftware/chronic/chronic.jsp [Accessed 13 Mar 2019].

2 Van Cleave J, Gortmaker SL, Perrin JM. Dynamics of obesity and chronic health conditions among children and youth. JAMA 2010;303:623-30.

3 van der Lee JH, Mokkink LB, Grootenhuis MA, et al. Definitions and measurement of chronic health conditions in childhood: a systematic review. JAMA 2007;297:2741-51.

4 WHO. Disease burden and mortality estimates: disease burden. WHO

5 Feudtner C, Christakis DA, Connell FA. Pediatric deaths attributable to complex chronic conditions: a population-based study of Washington state, 1980-1997. Pediatrics 2000;106:205-9.

6 Hanushek EA, Woessmann L, Ludger W. The role of cognitive skills in economic development. J Econ Lit 2008;46:607-68.

7 OECD. The high cost of low educational performance: the Long-run economic impact of improving Pisa outcomes. Paris: PISA, OECD Publishing, 2010.

8 Fardell EJ, Hu N, Wakefield EC. The impact of hospitalisations due to chronic health conditions in the first five years of life on early child development at school entry: a population study. Submitted 2020.

9 Bell MF, Bayliss DM, Glauert R, et al. Chronic illness and developmental vulnerability at school entry. Pediatrics 2016;137:e20152475.

10 Nasuuna E, Santoro G, Kremer P, et al. Examining the relationship between childhood health conditions and health service utilisation at school entry and subsequent academic performance in a large cohort of Australian children.J Paediatr Child Health 2016:52:750-8

11 Crump C, Rivera D, London R, et al. Chronic health conditions and school performance among children and youth. Ann Epidemiol 2013;23:179-84.

12 Cooper MN, McNamara KAR, de Klerk NH, et al. School performance in children with type 1 diabetes: a contemporary population-based study. Pediatr Diabetes 2016;17:101-11

13 Martin AJ, Collie RJ, Roberts C, et al. The role of medication in reducing the negative effects of hyperactivity-inattention on achievement: a population-based Iongitudinal investigation of students and their classrooms. Contemp Educ Psychol 2018:55:97-109.

14 Bentley JP, Schneuer FJ, Lain SJ, et al. Neonatal morbidity at term, early child development, and school performance: a population study. Pediatrics 2018;141. doi:10.1542/peds.2017-1726. [Epub ahead of print: 04 Jan 2018].

15 Australian Centre for Asthma Monitoring. Asthma in Australian children: findings from growing up in Australia, the longitudinal study of Australian Childrenn. cat. No. ACM 17. Canberra: Australia: AlHW, 2009.

16 Lum A, Wakefield CE, Donnan B, et al. School students with chronic illness have unmet academic, social, and emotional school needs. Sch Psychol 2019;34:627-36.

17 Kids to adults: chronic illness alliance. Available: https://www.kidstoadults.com/

18 Houng B, Justman M. NAPLAN scores as predictors of access to higher education in Victoria. Melbourne Institute working paper. Australia: Melbourne: University of Melbourne, 2014

19 ACARA. National assessment program - literacy and Numeracy 2013: technical report. Sydney, Australia: Australian Curriculum, Assessment and Reporting Authority, 2014.

20 Hardelid P, Dattani N, Gilbert R, et al. Estimating the prevalence of chronic conditions in children who die in England, Scotland and Wales: a data linkage cohort study. BMJ Open 2014;4:e05331.

21 Australian Bureau of Statistics. An introduction to socioeconomic indexes for areas (SEIFA), 2006. Canberra: Australian Bureau of Statistics, 2008.

22 The National Centre for Social Applications of GIS (GISCA). Accessibility/Remoteness index of Australia plus (version 2.0): methodology. Adelaide, SA, Australia: GISCA, The University of Adelaide, 2004

23 Bell J, Lingam R, Wakefield CE, et al. Prevalence, hospital admissions and costs of child chronic conditions: a population-based study. J Paediatr Child Health 2020:56:1365-70

24 ACARA. National assessment Program—- Literacy and Numeracy achievement in reading, writing, language conventions and Numeracy: national report for 2019. Sydney, Australia: Australian Curriculum, Assessment and Reporting Authority, 2019.

25 Allison MA, Attisha E, COUNCIL ON SCHOOL HEALTH. The link between school attendance and good health. Pediatrics 2019;143:e20183648.

26 Sentenac M, Gavin A, Gabhainn SN, et al. Peer victimization and subjective health among students reporting disability or chronic illness in 11 Western countries. Eur J Public Health 2013;23:421-6.

27 Janin MMH, Ellis SJ, Lum A, et al. Parents' perspectives on their child's social experience in the context of childhood chronic illness: a qualitative study. J Pediatr Nurs 2018:42:e10-18.

28 Vergison A, Dagan R, Arguedas A, et al. Otitis media and its consequences: beyond the earache. Lancet Infect Dis 2010:10:195-203.

29 Goodsell B, Lawrence D, Ainley J. Child and adolescent mental health and educational outcomes. An analysis of educational outcomes from young minds matter: the second Australian child and adolescent survey of mental health and Wellb. Perth: Graduate School of Education, The University of Western Australia, 2017.

30 Lum A, Wakefield CE, Donnan B, et al. Facilitating engagement with school in students with chronic illness through positive education: a mixed-methods comparison study. Sch Psychol 2019;34:677-86.

31 Hancock KJ, Shepherd CCJ, Lawrence D. Student attendance and educational outcomes: Every day counts. In: Report for the Department of education, employment and workplace relations. Canberra, 2013.

32 Duffner PK. Long-term effects of radiation therapy on cognitive and endocrine function in children with leukemia and brain tumors. Neurologist 2004;10:293-310. 